OPEN ACCESS

Edited by:

Peer Schenk,

The University of Queensland,

Australia

Reviewed by:

Martin Hagemann,

University of Rostock, Germany

Shuyi Zhang,

Massachusetts Institute

of Technology, United States

*Correspondence:

Takashi Osana

tosanai@meiji.ac.jp

Specialty section:

This article was submitted to

Plant Biotechnology,

a section of the journal

Frontiers in Plant Science

Received: 28 November 2017

Accepted: 12 June 2018

Published: 13 July 2018

Citation:

Takeya M, Ito S, Sukigara H and

Osanai T (2018) Purification

and Characterisation of Malate

Dehydrogenase From Synechocystis sp. PCC 6803: Biochemical Barrier

of the Oxidative Tricarboxylic Acid

Cycle. Front. Plant Sci. 9:947.

doi: 10.3389/fpls.2018.00947

\section{Purification and Characterisation of Malate Dehydrogenase From Synechocystis sp. PCC 6803: Biochemical Barrier of the Oxidative Tricarboxylic Acid Cycle}

\author{
Masahiro Takeya, Shoki Ito, Haruna Sukigara and Takashi Osanai* \\ School of Agriculture, Meiji University, Tokyo, Japan
}

Cyanobacteria possess an atypical tricarboxylic acid (TCA) cycle with various bypasses. Previous studies have suggested that a cyclic flow through the TCA cycle is not essential for cyanobacteria under normal growth conditions. The cyanobacterial TCA cycle is, thus, different from that in other bacteria, and the biochemical properties of enzymes in this TCA cycle are less understood. In this study, we reveal the biochemical characteristics of malate dehydrogenase (MDH) from Synechocystis sp. PCC 6803 $\mathrm{MDH}(\mathrm{SyMDH})$. The optimal temperature of SyMDH activity was $45-50^{\circ} \mathrm{C}$ and $\mathrm{SyMDH}$ was more thermostable than MDHs from other mesophilic microorganisms. The optimal $\mathrm{pH}$ of SyMDH varied with the direction of the reaction: $\mathrm{pH} 8.0$ for the oxidative reaction and $\mathrm{pH} 6.5$ for the reductive reaction. The reductive reaction catalysed by SyMDH was activated by magnesium ions and fumarate, indicating that SyMDH is regulated by a positive feedback mechanism. The $K_{\mathrm{m}}$-value of SyMDH for malate was approximately 210 -fold higher than that for oxaloacetate and the $K_{\mathrm{m}}$-value for $\mathrm{NAD}^{+}$ was approximately 19 -fold higher than that for $\mathrm{NADH}$. The catalytic efficiency of SyMDH for the reductive reaction, deduced from $k_{\text {cat }}$-values, was also higher than that for the oxidative reaction. These results indicate that SyMDH is more efficient in the reductive reaction in the TCA cycle, and it plays key roles in determining the direction of the TCA cycle in this cyanobacterium.

Keywords: biochemistry, cyanobacteria, malate dehydrogenase, metabolic enzyme, TCA cycle

\section{INTRODUCTION}

Cyanobacteria performing oxygenic photosynthesis synthesise various compounds from carbon dioxide using light energy. Cyanobacteria are widely used as hosts in metabolic engineering to produce renewable resources. Synechocystis sp. PCC 6803 (hereafter Synechocystis 6803) is one of the most highly studied cyanobacteria because it has many advantageous features, such as rapid proliferation and ease of transformation. Besides genetics, biochemical analyses of enzymes related to oxaloacetate metabolism proceed using Synechocystis 6803 enzymes (Ito et al., 2017; Takeya et al., 2017), and thus this cyanobacterium is widely used for basic studies of primary carbon metabolism. 
The tricarboxylic acid (TCA) cycle is one of the most important biochemical reactions in aerobic energy production, and is common among most respiring organisms. Reductants are generated by oxidation of metabolites through the TCA cycle, leading to ATP production through the process of respiration, which uses these reductants. Metabolites in the TCA cycle, such as oxaloacetate and 2-oxoglutarate, are precursors of various metabolites, including amino acids, sugars, and lipids (Owen et al., 2002). The cyanobacterial TCA cycle is also involved in various metabolic systems, which can lead to the production of useful materials, such as succinate (Osanai et al., 2015), amino acids (Matsunaga et al., 1991), ethylene (Xiong et al., 2015) via acetyl-CoA, and TCA cycle derivatives from fixing carbon dioxide by oxygenic photosynthesis using light energy.

Compared to studies on enzymes in the Calvin cycle, biochemical analysis of enzymes of the TCA cycle in cyanobacteria is limited. The cyanobacterial TCA cycle was once thought to be an incomplete cycle owing to the lack of 2-oxoglutarate dehydrogenase (OGDH); however, it has been demonstrated that 2-oxoglutarate decarboxylase and succinate semialdehyde dehydrogenase produce succinate from 2-oxoglutarate (Zhang and Bryant, 2011; Steinhauser et al., 2012). In addition, the $\gamma$-aminobutyric acid (GABA) shunt produces succinate from glutamate in Synechocystis 6803 (Xiong et al., 2014), and the glyoxylic acid shunt is found in the cyanobacterium Chlorogloeopsis fritschii strain PCC 9212 (Zhang and Bryant, 2015). Thus, the cyanobacterial TCA cycles are potentially closed with these alternative shunts. However, these studies only analysed the first half of the TCA cycle, from citrate to succinate. The latter half of the TCA cycle has been studied by in silico analysis (Knoop et al., 2013; Rubin et al., 2015). Kinetic values, such as $k_{\text {cat }}$ and $K_{\mathrm{m}}$, of cyanobacterial TCA cycle enzymes have not been determined, except for isocitrate dehydrogenase (Muro-Pastor and Florencio, 1992, 1994). Biochemical analysis of phosphoenolpyruvate carboxylase (PEPC), which produces oxaloacetate from phosphoenolpyruvate, reveals that Synechocystis 6803 PEPC is uniquely tolerant to feedback inhibition by malate and aspartate (Takeya et al., 2017). In addition to the oxidative cycle, the cyanobacterial TCA cycle reverses to a reductive reaction (called the reductive branch of the TCA cycle) under dark, anaerobic conditions (Hasunuma et al., 2016).

Malate dehydrogenase $(\mathrm{MDH})$ is an enzyme that catalyses the interconversion between malate and oxaloacetate using $\mathrm{NAD}(\mathrm{P}) \mathrm{H}$. MDHs are largely conserved in most species, irrespective of variation in the TCA cycle (Huynen et al., 1999; Minárik et al., 2002). MDH catalyses the oxidative reaction in the TCA cycle (malate to oxaloacetate) in vivo, although $\mathrm{MDH}$ thermodynamically prefers the reductive reaction (oxaloacetate to malate) in vitro (Molenaar et al., 1998). Thus, $\mathrm{MDH}$ is a unique enzyme that prefers the reductive reaction in the TCA cycle; however, the biochemical parameters of Synechocystis 6803 $\mathrm{MDH}(\mathrm{S} y \mathrm{MDH})$ have not been determined. $\mathrm{MDH}$ functions to protect against oxidative stress in Escherichia coli (Wu et al., 2007; Singh et al., 2008), also suggesting the physiological importance of MDHs in bacteria. In this study, $S y \mathrm{MDH}$ was purified, and its biochemical functions were demonstrated for the first time, revealing unique regulatory mechanisms of $S y \mathrm{MDH}$.

\section{MATERIALS AND METHODS}

\section{Construction of Cloning Vectors for Recombinant Protein Expression}

A BamHI-XhoI DNA fragment of the citH (sll0891) ORF from the Synechocystis 6803 genome was amplified by PCR using KOD Plus Neo polymerase (Toyobo, Osaka, Japan) with the primers: forward, GAAGGTCGTGGGATCATGAATATTTT GGAGTATGCTC and reverse, GATGCGGCCGCTCGAGT TAACCGTCGCTAACCAT. The resultant fragments were excised with BamHI-XhoI (Takara Bio, Shiga Japan) and cloned into the BamHI-XhoI site of pGEX5X-1 (GE Healthcare Japan, Tokyo, Japan) using the In-Fusion HD Cloning Kit (Takara Bio, Shiga, Japan). Sequence integrity was confirmed by sequencing.

\section{Affinity Purification of Recombinant Proteins}

Expression vectors were transformed into E. coli BL21 (DH5 $\alpha$, Takara Bio). Two litres of $E$. coli containing the vectors were cultivated at $30^{\circ} \mathrm{C}$ with shaking $(150 \mathrm{rpm})$, and protein expression was induced overnight by adding $0.01 \mathrm{mM}$ isopropyl $\beta$-D-1-thiogalactopyranoside (Wako Chemicals, Osaka, Japan).

Affinity chromatography was performed for protein purification as described in a previous study (Osanai et al., 2009). Two litres of E. coli cell culture were disrupted by sonication VC-750 (EYELA, Tokyo, Japan) for 5 min with 30\% intensity and centrifuged at $5,800 \times g$ for $2 \mathrm{~min}$ at $4^{\circ} \mathrm{C}$. The supernatant was transferred to a new $50-\mathrm{mL}$ plastic tube on ice and $640 \mu \mathrm{L}$ of glutathione-Sepharose $4 \mathrm{~B}$ resin (GE Healthcare Japan) was mixed into the supernatant. After gentle rotating for $30 \mathrm{~min}, 1 \mathrm{mM}$ ATP and $1 \mathrm{mM} \mathrm{MgSO} 4 \cdot 7 \mathrm{H}_{2} \mathrm{O}$ were added and samples were incubated with gentle shaking for $30 \mathrm{~min}$ to remove intracellular chaperons. After centrifugation $(5,800 \times g$ for $2 \mathrm{~min}$ at $4^{\circ} \mathrm{C}$ ), the supernatant was removed and resins were re-suspended in $700 \mu \mathrm{L}$ of PBS-T (1.37 M NaCl, $27 \mathrm{mM}$ $\mathrm{KCl}, 81 \mathrm{mM} \mathrm{Na} \mathrm{HPO}_{4} \cdot 12 \mathrm{H}_{2} \mathrm{O}, 14.7 \mathrm{mM} \mathrm{KH} \mathrm{KO}_{4}, 0.05 \%$ Tween-20) with $1 \mathrm{mM}$ ATP/1 mM $\mathrm{MgSO}_{4} \cdot 7 \mathrm{H}_{2} \mathrm{O}$. The resin was washed with $500 \mu \mathrm{L}$ of PBS-T $(1.37 \mathrm{M} \mathrm{NaCl}, 27 \mathrm{mM}$ $\mathrm{KCl}, 81 \mathrm{mM} \mathrm{Na} \mathrm{HPO}_{4} \cdot 12 \mathrm{H}_{2} \mathrm{O}, 14.7 \mathrm{mM} \mathrm{KH} \mathrm{KO}_{4}, 0.05 \%$ Tween-20) and eluted three times with $500 \mu \mathrm{L}$ of GST elution buffer (50 mM Tris- $\mathrm{HCl}, \mathrm{pH} 8.0,10 \mathrm{mM}$ reduced glutathione). Proteins were concentrated with VivaSpin 500 MWCO 50,000 spin columns (Sartorius, Göttingen, Germany) and protein concentration was measured with a PIERCE BCA Protein Assay Kit (Thermo Fisher Scientific, Rockford, IL, United States). Protein purification was validated by SDS-PAGE, including staining using InstantBlue (Expedion Protein Solutions, San Diego, CA, United States).

\section{Enzyme Assays}

$7.8 \mu \mathrm{g}$ or $10 \mu \mathrm{g}$ of $\mathrm{SyMDHs}$ were used to measure oxidative or reductive reactions, respectively. The purified protein was 
mixed with $1 \mathrm{~mL}$ of assay solution (100 mM potassium phosphate buffer [pH 8.0 or $\mathrm{pH}$ 6.5], 0.1-32 $\mathrm{mM}$ nicotinamide adenine dinucleotide $\left(\mathrm{NAD}^{+}\right), 0.01-0.64 \mathrm{mM}$ nicotinamide adenine dinucleotide hydride (NADH), 0.2-32 mM malate, 0.02-0.4 mM oxaloacetate). The optimal temperature and the optimal $\mathrm{pH}$ were measured at the concentration exhibiting maximum activity $\left(\mathrm{NAD}^{+}\right.$: $8.0 \mathrm{mM}$, NADH: $0.1 \mathrm{mM}$, malate: $4.0 \mathrm{mM}$, oxaloacetate: $0.1 \mathrm{mM})$. For the cell extract assay, cells from $1 \mathrm{~L}$ culture were collected by centrifugation and resuspend in $100 \mathrm{mM}$ potassium phosphate buffer (pH7.0). The cells were disrupted by sonication and centrifuged at $5,800 \times g$ for $30 \mathrm{~min}$ at $4^{\circ} \mathrm{C}$. The protein concentration was quantified with BCA Protein Assay Kit (Thermo) and $420 \mu \mathrm{g}$ of total proteins was added to $1 \mathrm{~mL}$ assay solution. Absorbance was measured at $340 \mathrm{~nm}$ using a UV-1850 spectrophotometer (Shimadzu, Tokyo, Japan). $V_{\max }$ and $K_{\mathrm{m}}$-values were determined using a LineweaverBurk double reciprocal plot. Results were plotted as a graph of the rate of reaction against the concentration of substrate and coenzyme using Kaleida Graph ver. 4.5 software. When the data did not show substrate inhibition, we performed curve fitting used the Michaelis-Menten equation (Eq. 1). When the data exhibited substrate inhibition, we performed curve fitting using the modified Michaelis-Menten equation (Eq. 2) (Eszes et al., 1996).

$$
v=V_{\max }[S] /\left([S]+K_{\mathrm{m}}\right)
$$

$$
v=V_{\max }[S] /\left([S]+K_{\mathrm{m}}+[S]^{2} / K_{\mathrm{i}}\right)
$$

$v$ and $V_{\max }$ indicate reaction velocity and maximum reaction velocity, respectively. [S], $K_{\mathrm{m}}$, and $K_{\mathrm{i}}$ indicate substrate concentration, the half-maximum concentration giving rise to $50 \% V_{\max }$ and an inhibition constant, respectively.

\section{RESULTS}

\section{Measurement of Kinetic Parameters}

To determine the kinetic parameters of $S y \mathrm{MDH}$, glutathione $S$-transferase (GST)-tagged SyMDH (GST-SyMDH) proteins were expressed in E. coli and purified by affinity chromatography (Figure 1A). SyMDH activity in the oxidative reaction (malate to oxaloacetate) was the highest at $\mathrm{pH} 8.0$ and at a temperature of $50^{\circ} \mathrm{C}$ (Figures 1B,C). SyMDH activity in the reductive reaction (oxaloacetate to malate) was the highest at $\mathrm{pH} 6.5$ and at $45^{\circ} \mathrm{C}$ (Figures 1B,C). Kinetic parameters of $S y \mathrm{MDH}$ were determined by a Lineweaver-Burk double reciprocal plot using the specific activity values in Figures 2, 3. These results are summarised in Tables 1, 2. SyMDH displayed approximately 1.7 -fold $\left(k_{\text {cat }}\right)$ and 361 -fold $\left(k_{\text {cat }} / K_{m}\right)$ preferences for oxaloacetate reduction over malate oxidation and approximately 4.7 -fold $\left(k_{\mathrm{cat}}\right)$ and 90.5fold $\left(k_{\text {cat }} / K_{m}\right)$ preferences for $\mathrm{NADH}$ oxidation over $\mathrm{NAD}^{+}$
A

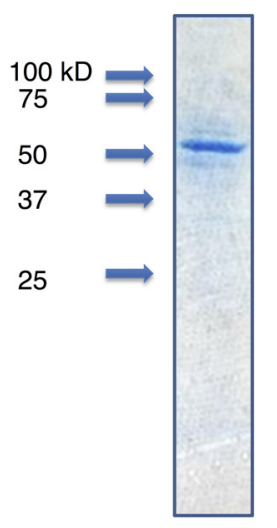

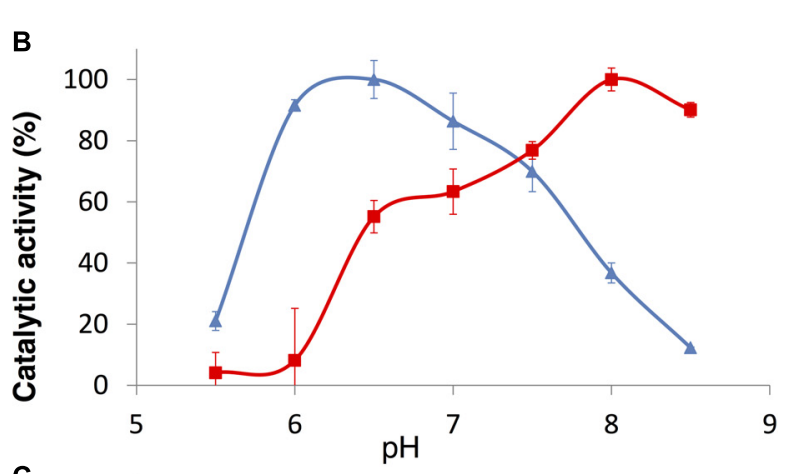

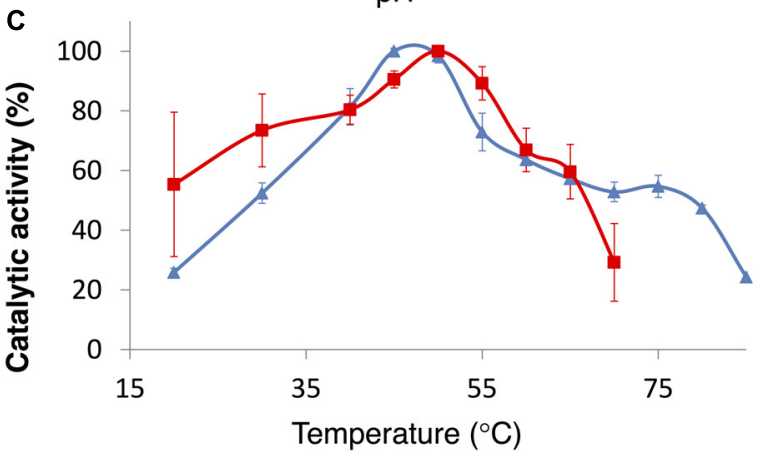

FIGURE 1 | (A) Purification of GST-tagged SyMDH. Proteins were electrophoresed on a 12\% SDS-PAGE gel. The gel was stained with InstantBlue. Arrowheads indicate the molecular weight. (B) The effect of $\mathrm{pH}$ on SyMDH activity. Red square represents the specific activity in the oxidative reaction (malate to oxaloacetate). Blue triangle represents the specific activity in the reductive reaction (oxaloacetate to malate). Data represent the relative values of the mean from three independent experiments. (C) The effect of temperature on SyMDH activity. Red square represents the specific activity in the oxidative reaction (malate to oxaloacetate). Blue triangle represents the specific activity in the reductive reaction (oxaloacetate to malate). Data represent the relative values of the mean from three independent experiments. 

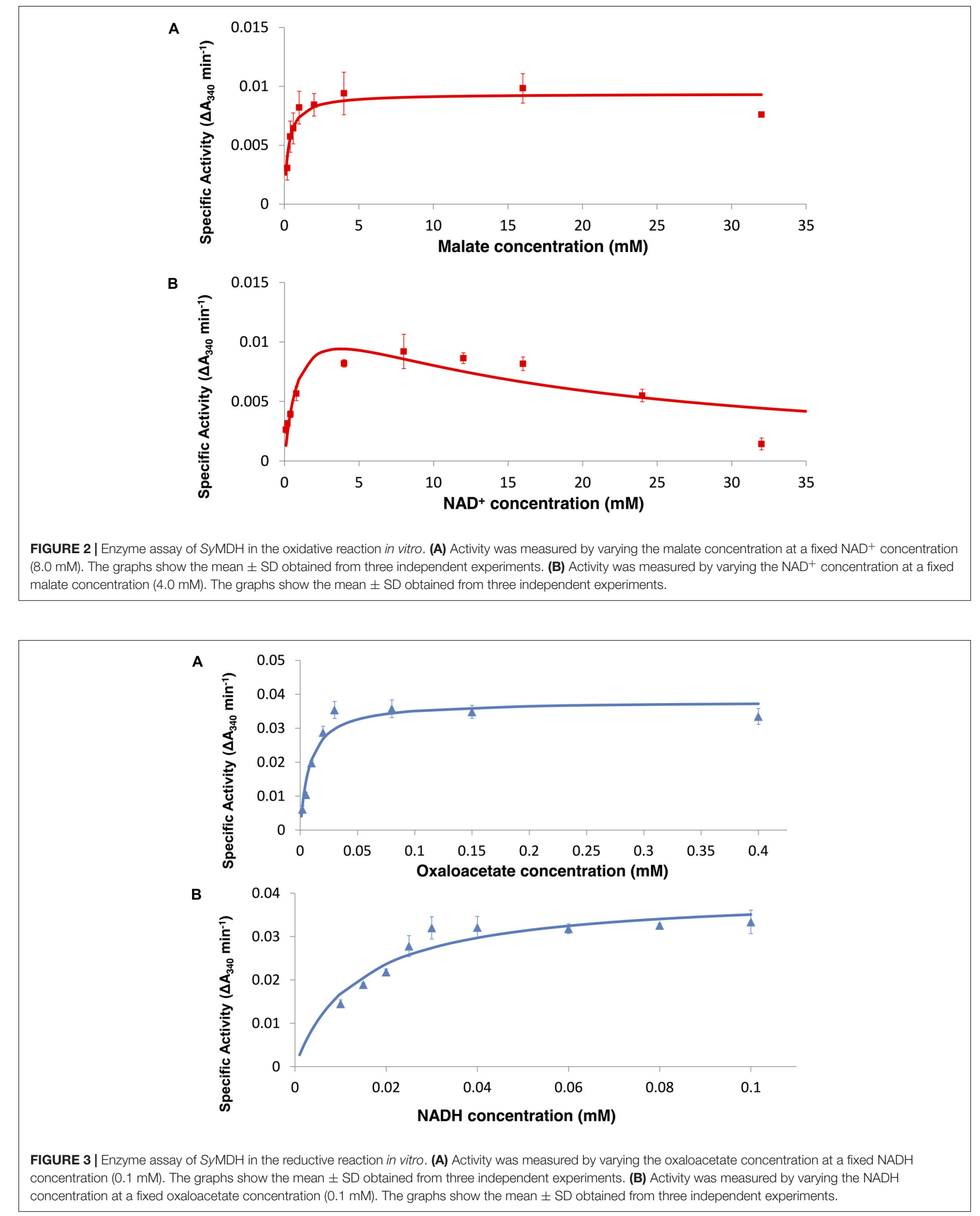
TABLE 1 | Kinetic parameters of SyMDH.

\begin{tabular}{|c|c|c|c|}
\hline & $\begin{array}{c}V_{\max } \\
\text { (units. } \mathrm{mg}^{-1} \text { ) }\end{array}$ & $\begin{array}{l}k_{\text {cat }} \\
\left(s^{-1}\right)\end{array}$ & $\begin{array}{c}k_{\text {cat }} / K_{\mathrm{m}} \\
\left(\mathrm{s}^{-1} \cdot \mathrm{mM}^{-1}\right)\end{array}$ \\
\hline Malate & 0.412 & 0.43 & 0.165 \\
\hline OAA & 0.685 & 0.71 & 59.5 \\
\hline $\mathrm{NAD}^{+}$ & 0.199 & 0.21 & 0.357 \\
\hline $\mathrm{NADH}$ & 0.931 & 0.97 & 32.3 \\
\hline
\end{tabular}

The oxidative reaction (malate to oxaloacetate) was assayed in $100 \mathrm{mM}$ potassium phosphate buffer $(\mathrm{pH}$ 8.0) by varying the malate concentration at a fixed $\mathrm{NAD}^{+}$concentration $(8.0 \mathrm{mM})$ or by varying the $\mathrm{NAD}^{+}$concentration at a fixed malate concentration $(4.0 \mathrm{mM})$. The reductive reaction (oxaloacetate to malate) was assayed in $100 \mathrm{mM}$ potassium phosphate buffer ( $\mathrm{pH}$ 6.5) by varying the oxaloacetate concentration at a fixed $\mathrm{NADH}$ concentration $(0.1 \mathrm{mM})$ or by varying the NADH concentration at a fixed oxaloacetate concentration $(0.1 \mathrm{mM})$. The kinetic parameters were calculated by the Lineweaver-Burk plot. The values of $k_{\text {cat }}$ were calculated by dividing $V_{\max }$ by the molar amounts of SyMDH proteins.

reduction (Table $\mathbf{1}$ ). The catalytic efficiency of the reductive reaction was higher than that of the oxidation reaction for both the substrate and the coenzyme. The $K_{\mathrm{m}}$-value for malate was approximately 210 -fold higher than that for oxaloacetate, and the $K_{\mathrm{m}}$-value for $\mathrm{NAD}^{+}$was approximately 19 -fold higher than that for NADH (Table 2). SyMDH appeared to prefer oxaloacetate and $\mathrm{NADH}$ as substrate and coenzyme, respectively, in vitro. SyMDH had enzymatic activity toward $\mathrm{NAD}^{+}$and NADH, but no activity toward $\mathrm{NADP}^{+}$and NADPH both in vitro and in vivo (Supplementary Figures S1, S2). We also determined kinetic parameters of $\mathrm{SyMDH}$ using the Michaelis-Menten equation. These results are summarised in Supplementary Tables S1, S2. These calculations showed that $S y \mathrm{MDH}$ prefers oxaloacetate and $\mathrm{NADH}$ as substrate and coenzyme, respectively; the $K_{\mathrm{m}}$-value for malate was approximately 84.4-fold higher than that for oxaloacetate, and the $K_{\mathrm{m}}$-value for $\mathrm{NAD}^{+}$was approximately 71.4-fold higher than that for NADH (Supplementary Table S2). SyMDH exhibited substrate inhibition by $\mathrm{NAD}^{+}$(Figure 2B), and the value of $K_{\mathrm{i}}$ was $14.5 \mathrm{mM}$ (Supplementary Table S1).

\section{Effect of Various Effectors on SyMDH Activity}

The reductive reaction catalysed by bacterial MDHs is inhibited by TCA cycle metabolites, such as excess oxaloacetate and divalent metal ions (Takahashi-Íñiguez et al., 2016). Therefore, we measured the activity of $S y \mathrm{MDH}$ in the reductive reaction in the presence of various effectors. $S y \mathrm{MDH}$ was inhibited by excess $\mathrm{NAD}^{+}$in the reductive reaction (Figure 2B). With the exception of cobalt, magnesium, and copper ions, all other metal ions showed little effect on $S y \mathrm{MDH}$ (Figure 4). SyMDH activity increased approximately 140 and $160 \%$ with the addition of $1 \mathrm{mM}$ $\mathrm{Co}\left(\mathrm{NO}_{3}\right)_{2} \cdot 6 \mathrm{H}_{2} \mathrm{O}$ and $1 \mathrm{mM} \mathrm{MgCl}$, respectively (Figure 4). In the presence of $10 \mathrm{mM} \mathrm{MgCl}_{2}$, the activity of $S y \mathrm{MDH}$ increased to approximately 190\% (Figure 4). Among the metal ions tested, only copper ions reduced the activity of $S y \mathrm{MDH}$. In the presence of $1 \mathrm{mM} \mathrm{CuSO} 4 \cdot 5 \mathrm{H}_{2} \mathrm{O}, S y \mathrm{MDH}$ activity decreased to approximately $40 \%$ of normal activity (Figure 4). SyMDH activity could not be measured in the presence of $10 \mathrm{mM}$ calcium, manganese, cobalt, zinc, or copper ions due to the formation of a precipitate (Figure 4). SyMDH activity rose approximately 170 and $190 \%$ with the addition of 1 and $10 \mathrm{mM}$ fumarate, respectively (Figure 4). SyMDH activity with oxaloacetate at a concentration of 0.01-0.6 mM was measured in the presence of $10 \mathrm{mM}$ magnesium and fumarate, and the kinetic parameters were calculated by Lineweaver-Burk plots (Figure 5A). Both the $K_{\mathrm{m}}$ and $V_{\text {max }}$-values of this substrate and reaction, respectively, increased with the addition of $10 \mathrm{mM} \mathrm{MgCl} 2$ and fumarate (Figures 5B,C). To strengthen the validity of our results, we also performed biochemical assays using cell extracts (Supplementary Figure S3a). Unlike in vitro, the $K_{\mathrm{m}}$-value did not change in vivo in the presence of $10 \mathrm{mM} \mathrm{MgCl} 2$ and fumarate (Supplementary Figure $\mathrm{S} 3 \mathrm{~b}$ ). The $V_{\max }$-value increased in vivo similar to in vitro in the presence of $10 \mathrm{mM} \mathrm{MgCl}_{2}$ and fumarate (Supplementary Figure S3c).

\section{Thermal Properties of SyMDH Activity}

Synechocystis $6803 \mathrm{MDH}$ activity was measured by varying temperature $\left(20-50^{\circ} \mathrm{C}\right)$. The $K_{\mathrm{m}}$ and the $V_{\max }$ were calculated by both a Lineweaver-Burk double reciprocal plot (Figures 5, 6) and curve fitting used the Michaelis-Menten equation (Supplementary Figures $\mathrm{S} 4, \mathrm{~S} 5$ ). The $K_{\mathrm{m}}$ and the $V_{\max }$-values for malate tend to decrease as the temperature rise, although the $V_{\max }$-values less dependent on the temperature (Figure 6 and Supplementary Figure S4). On the contrary, the $K_{\mathrm{m}}$ and

TABLE 2 | Comparison of $K_{m}$-values of MDHs in various microorganisms.

\begin{tabular}{|c|c|c|c|c|c|c|c|}
\hline$K_{\mathrm{m}}(\mu \mathrm{M})$ & Malate & OAA & $\mathbf{N A D}^{+}$ & NADH & Malate/OAA & $\mathrm{NAD}^{+} / \mathrm{NADH}$ & Reference \\
\hline Nitrosomonas europaea & 5000 & 20 & 24 & 22 & 250 & 1.1 & Deutch, 2013 \\
\hline Synechocystis sp. PCC 6803 & 2600 & 12 & 580 & 30 & 216.7 & 19.3 & This study \\
\hline Syntrophic propionate-oxidising bacterium strain MPOB & 4000 & 50 & 1100 & 30 & 80 & 36.7 & van Kuijk and Stams, 1996 \\
\hline Methanobacterium thermoautotrophicum & 400 & 30 & 90 & 90 & 13.3 & 1 & Thompson et al., 1997 \\
\hline Bacillus subtilis B1 & 260 & 22 & 100 & 14 & 11.8 & 7.1 & Wynne et al., 1996 \\
\hline Haemophilus parasuis & 550 & 72 & 120 & 17 & 7.6 & 7.1 & Wise et al., 1997 \\
\hline Streptomyces coelicolor & 490 & 190 & 150 & 83 & 2.6 & 1.8 & Ge et al., 2010 \\
\hline Pseudomonas stutzeri & 63 & 32 & 340 & 36 & 2 & 9.4 & Labrou and Clonis, 1997 \\
\hline Helicobacter pylori & 180 & 130 & 160 & 65 & 1.4 & 2.5 & Pitson et al., 1999 \\
\hline Methanothermus fervidus & 150 & 200 & 140 & 5 & 0.8 & 28 & Honka et al., 1990 \\
\hline
\end{tabular}

$K_{m}$-values are listed in ascending order of $K_{m}$ for malate/ $K_{m}$ for oxaloacetate. $K_{m}$-values were calculated by the Lineweaver-Burk plot. 


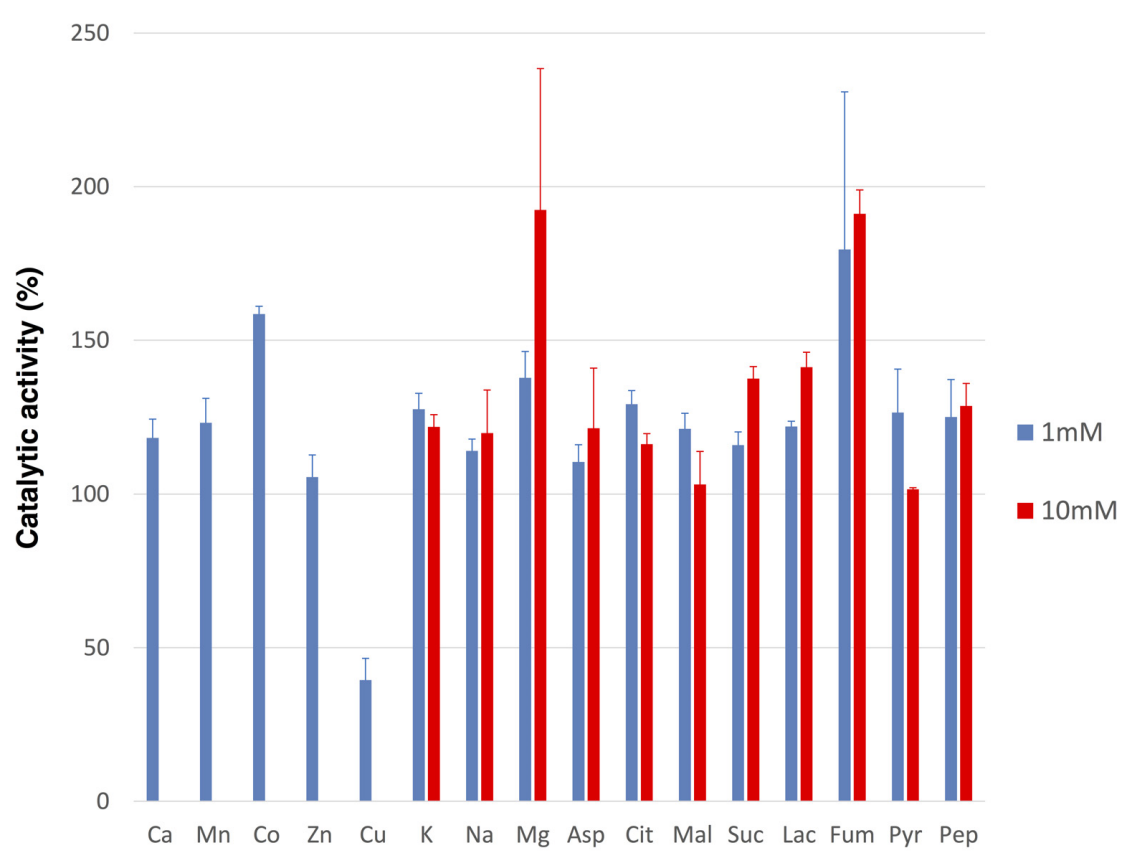

FIGURE 4 | Effects of various metal ions and compounds on the SyMDH in the reductive reaction in vitro. $10 \mu \mathrm{g}$ of SyMDH was pre-incubated with $100 \mathrm{mM}$ potassium phosphate $\left(\mathrm{pH}\right.$ 6.5), $0.1 \mathrm{mM} \mathrm{NADH}, 0.1 \mathrm{mM}$ oxaloacetate and effectors, at $45^{\circ} \mathrm{C}$. The graphs show the mean $\pm \mathrm{SD}$ obtained from three independent

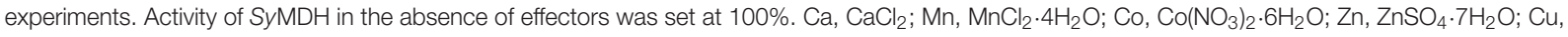
$\mathrm{CuSO}_{4} \cdot 5 \mathrm{H}_{2} \mathrm{O} ; \mathrm{K}, \mathrm{KCl} ; \mathrm{Na}, \mathrm{NaCl} ; \mathrm{Mg}, \mathrm{MgCl}_{2}$; Asp, L-Aspartate; Cit, Citrate; Mal, L-Malate; Suc, Succinate; Lac, L-lactate; Fum, Fumarate; Pyr, Pyruvate; Pep, Phosphoenolpyruvate.

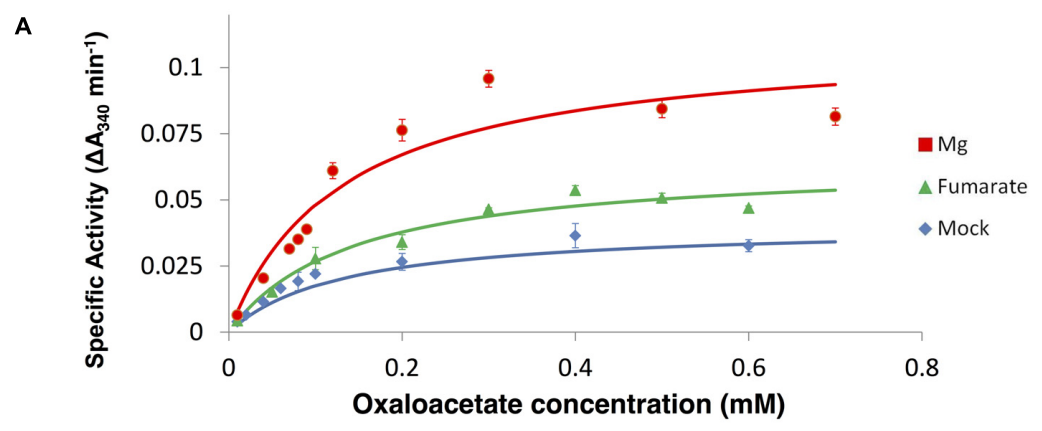

B

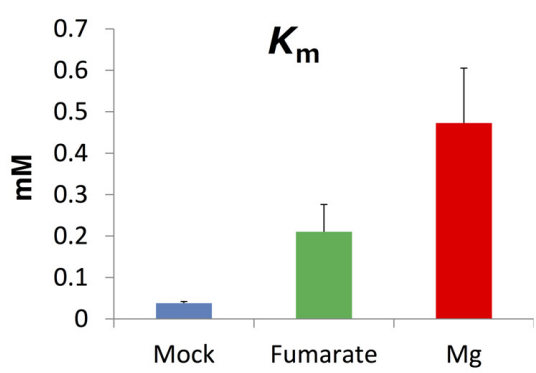

C

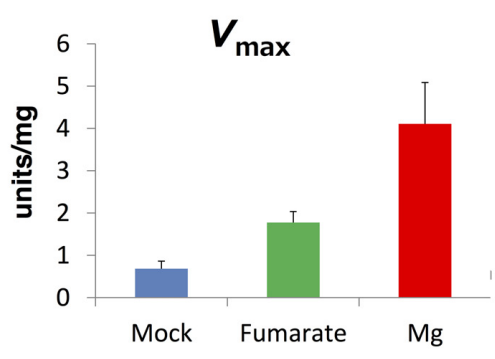

FIGURE $\mathbf{5}$ | The $K_{\mathrm{m}}$ and $V_{\max }$-values for oxaloacetate in the presence of $10 \mathrm{mM}$ fumarate and $10 \mathrm{mM}$ magnesium ion in vitro. (A) Saturation curves of the activity of SyMDH. Blue line indicates mock, green line indicates presence of fumarate, and red line indicates the presence of magnesium. The graph shows the mean of three independent experiments. (B) $K_{\mathrm{m}}$ (mean $\pm \mathrm{SD}$ ) (units/mg protein) values in the presence of $10 \mathrm{mM}$ fumarate and $10 \mathrm{mM}$ magnesium ion, obtained from three independent experiments. (C) $V_{\max }$ (mean \pm SD) values for oxaloacetate, obtained from three independent experiments. Mock indicates the enzymatic activity in the absence of additional compounds. 


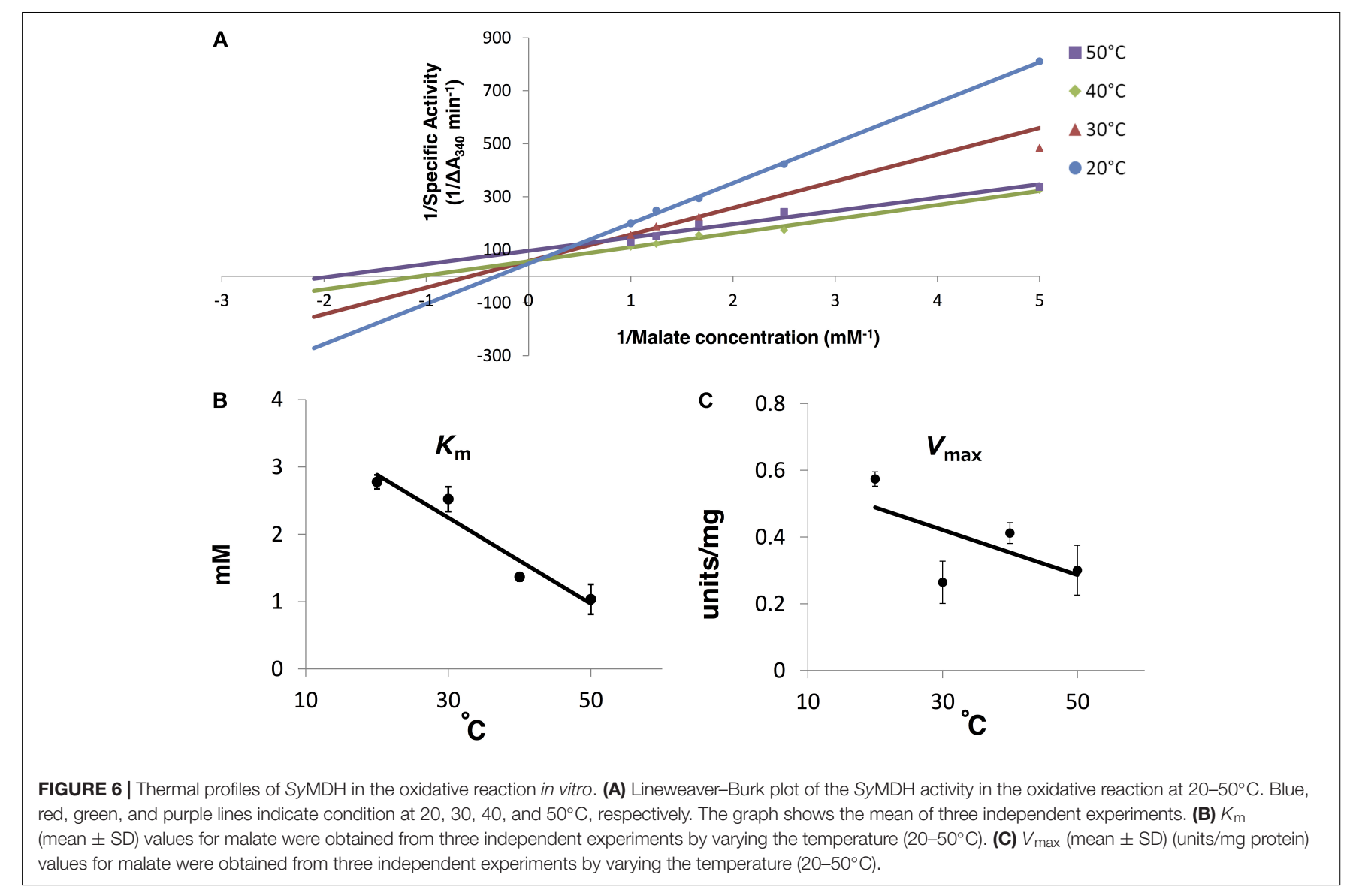

the $V_{\max }$-values for oxaloacetate increased as the temperature rise (Figure 7 and Supplementary Figure S5). The $K_{\mathrm{m}}$ and the $V_{\max }$ for malate at $20^{\circ} \mathrm{C}$ were approximately 2.7 -fold and 1.9-fold higher than that at $50^{\circ} \mathrm{C}$, respectively (Figure 6). The $K_{\mathrm{m}}$ and $V_{\max }$ for oxaloacetate at $20^{\circ} \mathrm{C}$ were approximately 0.19 and 0.13 -fold higher than that at $50^{\circ} \mathrm{C}$, respectively (Figure 7). The $K_{\mathrm{m}}$ and $V_{\max }$ of $S y \mathrm{MDH}$ demonstrated its temperature dependency.

\section{DISCUSSION}

We purified recombinant SyMDH protein and revealed the biochemical properties of cyanobacterial MDH for the first time. The optimal $\mathrm{pH}$ of $S y \mathrm{MDH}$ was different for the oxidative reaction and the reductive reaction (Figure 1B). Cyanobacteria utilise a reductive branch of TCA cycle and excrete succinate under dark anaerobic conditions (Hasunuma et al., 2016). The intracellular $\mathrm{pH}$ of cyanobacteria decreases during the transition from light to dark conditions (Coleman and Coleman, 1981; Mangan et al., 2016). Therefore, to adapt to the drastic changes in primary metabolism during the light and dark cycle, $S y \mathrm{MDH}$ is thought to shift its substrate affinity according to the intracellular $\mathrm{pH}$. SyMDH was stable at a wide range of temperature, being particularly tolerant to high temperatures (Figure 1C). Among the mesophilic microorganisms, MDHs from Streptomyces avermitilis, Streptomyces coelicolor, and Nitrosomonas europaea maintain their activity at $50^{\circ} \mathrm{C}$ (Mikulášová et al., 1998; Ge et al., 2010; Deutch, 2013), but these MDHs are completely inactivated at $60-70^{\circ} \mathrm{C}$ (Mikulášová et al., 1998; Ge et al., 2010; Deutch, 2013). SyMDH maintains its activity in both oxidative and reductive reactions at $60-70^{\circ} \mathrm{C}$ (Figure 1C). Therefore, SyMDH is the most thermostable enzyme among MDHs from the mesophilic microorganisms investigated thus far. The optimal temperatures of $S y \mathrm{MDH}$ were 50 and $45^{\circ} \mathrm{C}$, for the oxidative and reductive reaction, respectively (Figure 1C). Thus, optimal temperature of $5 y \mathrm{MDH}\left(45-50^{\circ} \mathrm{C}\right)$ and optimal growth temperature of Synechocystis $6803\left(30-35^{\circ} \mathrm{C}\right)$ were different. Generally, an enzymatic reaction is promoted by increasing temperature, because the kinetic energy of the reactants increases. However, an enzyme denature at high temperatures. Since SyMDH is a heat-stable enzyme (Figure 1B), the enzyme activity became the highest at around $50^{\circ} \mathrm{C}$, which is higher than the optimal growth temperature in Synechocystis 6803. Besides Synechocystis 6803, microorganisms having the MDHs with the optimal temperature much higher than the optimal growth temperature are $S$. avermitilis and S. coelicolor, N. europaea (Mikulášová et al., 1998; Ge et al., 2010; Deutch, 2013). SyMDH activity was suppressed by copper (Figure 4), as was observed for the MDH from Pseudomonas stutzeri (Labrou and Clonis, 1997). P. stutzeri MDH is also inhibited by citrate (Labrou and Clonis, 1997), but SyMDH was slightly activated by citrate (Figure 4). 

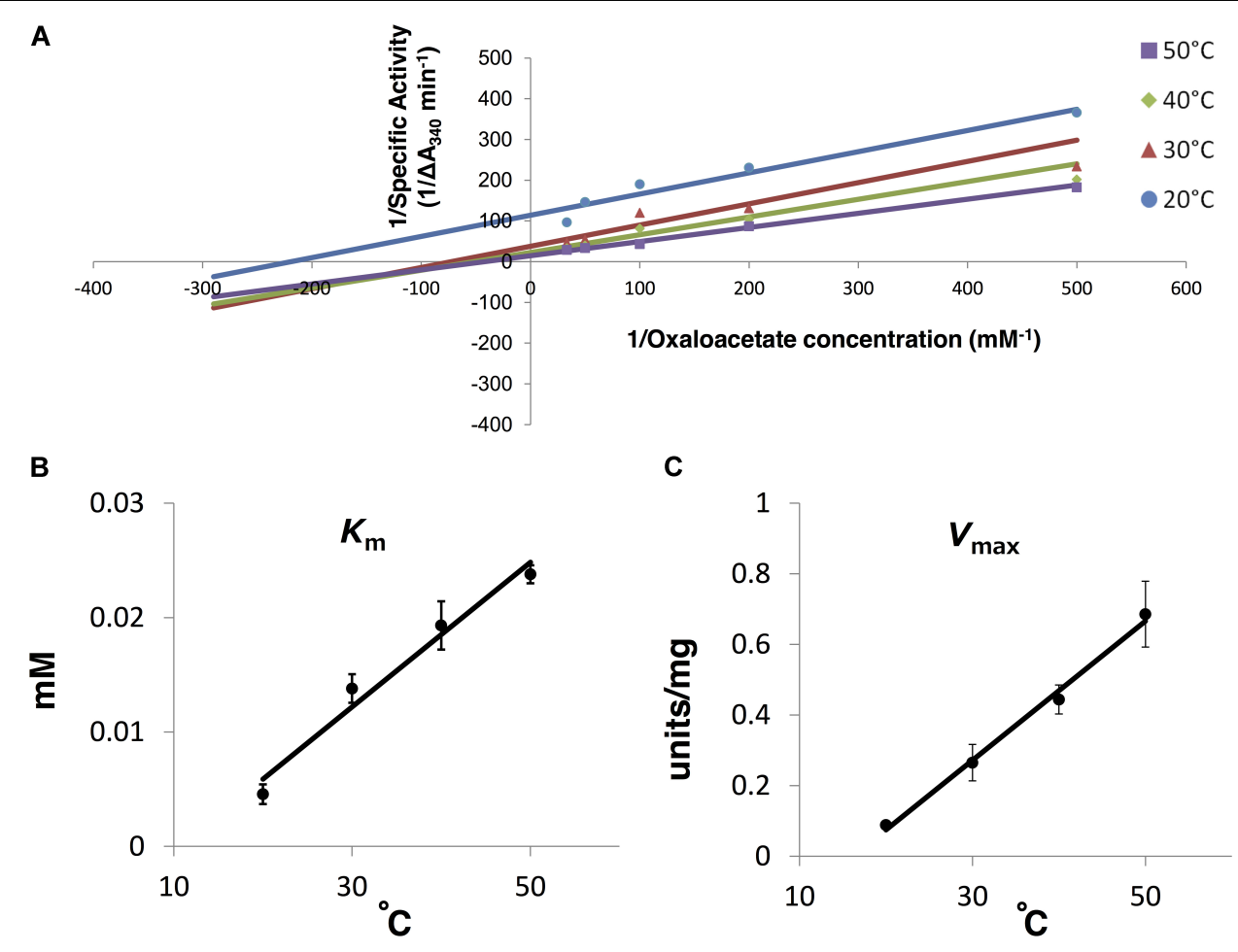

FIGURE 7 | Thermal profiles of SyMDH in the reductive reaction in vitro. (A) Lineweaver-Burk plot of the SyMDH activity in the reductive reaction at $20-50^{\circ} \mathrm{C}$. Blue, red, green, and purple lines indicate condition at $20,30,40$, and $50^{\circ} \mathrm{C}$, respectively. The graph shows the mean of three independent experiments. (B) $K_{\mathrm{m}}$ (mean $\pm \mathrm{SD}$ ) values for oxaloacetate were obtained from three independent experiments by varying the temperature (20-50 ${ }^{\circ} \mathrm{C}$ ). (C) $V_{\text {max }}$ (mean $\pm \mathrm{SD}$ ) (units/mg protein) values for oxaloacetate were obtained from three independent experiments by varying the temperature $\left(20-50^{\circ} \mathrm{C}\right)$.

The only reported activators of bacterial $\mathrm{MDHs}$ are $>0.18 \mathrm{mM}$ malate and $3 \mathrm{M} \mathrm{NaCl}$ (Cendrin et al., 1997; Labrou and Clonis, 1997), but $S y \mathrm{MDH}$ was significantly activated by magnesium ions and fumarate (Figure 5 and Supplementary Figure S3), suggesting that $S y \mathrm{MDH}$ is regulated by a positive feedback mechanism. These results are indicative of the diversity of regulation among $\mathrm{MDH}$. Intracellular concentrations of malate and fumarate in E. coli cells are 1.7 and $0.11 \mathrm{mM}$, respectively (Bennett et al., 2009). Since SyMDH showed maximum activity at $5 \mathrm{mM}$ malate (Figure 2) and was activated with $1 \mathrm{mM}$ fumarate (Figure 4), it is plausible that $S y \mathrm{MDH}$ activity was regulated by the TCA cycle metabolites. Excess $\mathrm{NAD}^{+}(>4 \mathrm{mM})$ caused substrate inhibition in SyMDH (Figure 2B). MDHs from Methanobacterium thermoautotrophicum and P. stutzeri are also inhibited by excess $\mathrm{NAD}^{+}(>0.5 \mathrm{mM})$ and $\mathrm{NAD}^{+}$ (>250 mM), respectively (Labrou and Clonis, 1997; Thompson et al., 1997). Intracellular concentrations of $\mathrm{NAD}^{+}$in E. coli cells is $2.6 \mathrm{mM}$ (Bennett et al., 2009), thus, SyMDH activity is thought to inhibited by $\mathrm{NAD}^{+}$present in Synechocystis 6803.

The affinity of oxaloacetate and $\mathrm{NADH}$ for $S y \mathrm{MDH}$ was higher than the affinity of malate and $\mathrm{NAD}^{+}$, respectively (Table 1). Generally, bacterial MDHs show higher affinity for oxaloacetate than malate (Takahashi-Íñiguez et al., 2016), and $\mathrm{SyMDH}$ was consistent with this. When comparing the substrate affinity among bacterial MDHs, the $K_{\mathrm{m}}$ (malate) $/ K_{\mathrm{m}}$ (oxaloacetate) ratio in descending order is as follows: N. europaea (250), Synechocystis 6803 (210), Syntrophic propionate-oxidising bacterium strain MPOB (80.0), and Methanobacterium thermoautotrophicum (13.3) (Table 2). The previous study demonstrated that the $\mathrm{NAD}^{+}$ concentration is approximately 500 times higher than NADH concentration in Synechocystis 6803 (Osanai et al., 2014). Therefore, although our biochemical analysis showed that SyMDH has higher coenzyme specificity toward $\mathrm{NADH}$ than $\mathrm{NAD}^{+}$, SyMDH can catalyse both reductive and oxidative reactions in vivo. The $K_{\mathrm{m}}\left(\mathrm{NAD}^{+}\right) / K_{\mathrm{m}}(\mathrm{NADH})$ ratio in descending order is as follows: Syntrophic propionate-oxidising bacterium strain MPOB (36.7), Methanothermus fervidus (28.0), and Synechocystis 6803 (19.0). These aforementioned microorganisms are thought to have low $\mathrm{MDH}$ activity in the oxidation reaction. This is because $N$. europaea is deficient in 2-oxoglutarate dehydrogenase (Beyer et al., 2009) and succinyl-CoA is formed via phosphoenolpyruvate and oxaloacetate using a reductive branch of TCA cycle (Deutch, 2013). In addition, syntrophic propionate-oxidising bacterium strain MPOB, Methanobacterium thermoautotrophicum, and Methanothermus fervidus are anaerobic microorganisms (Harmsen et al., 1996; Thompson et al., 1997; Stetter et al., 1981), and therefore, their oxidative TCA cycles are barely functioning. As with microorganisms in which the oxidative TCA cycle does not appear to function, the $K_{\mathrm{m}}$ (for malate) $/ K_{\mathrm{m}}$ (for 
oxaloacetate) ratio and the $K_{\mathrm{m}}\left(\mathrm{NAD}^{+}\right) / K_{\mathrm{m}}(\mathrm{NADH})$ ratio of $S y \mathrm{MDH}$ were very high. Therefore, $S y \mathrm{MDH}$ is likely to have low activity in the oxidative reaction. This conclusion is supported by flux analyses. Previous studies measured metabolic flow by estimating the flux rates of metabolites per dry cell weight (DCW) per unit hour in Synechocystis 6803 under mixotrophic conditions and found that all fluxes in TCA cycle reactions were clockwise $(0.02-0.11 \mathrm{mmol}$ $\left.\mathrm{gDCW}^{-1} \mathrm{~h}^{-1}\right)$, except for the interconversion between malate and oxaloacetate, which was anticlockwise $(0.13 \mathrm{mmol}$ $\mathrm{gDCW}^{-1} \mathrm{~h}^{-1}$; Nakajima et al., 2014). Similar results were observed under photoheterotrophic, nitrogen-limited, and dark conditions (Nakajima et al., 2014, 2017; Wan et al., 2017). In vivo studies have shown that many genes of the cyanobacterial TCA cycle are unnecessary for normal growth (Broddrick et al., 2016). Even if expression of fumarase, which catalyses the reversible hydration/dehydration of fumarate to malate, is blocked, growth of cyanobacteria under continuous light is not affected (Rubin et al., 2015). Therefore, the oxidative reaction of $S y \mathrm{MDH}$ is also thought to be unnecessary in cyanobacteria, because fumarase-deficient cyanobacteria grow normally. These studies support our biochemical studies suggesting that the oxidative reaction of $S y \mathrm{MDH}$ is very weak and almost non-functional. The kinetic parameters of SyMDH were affected by temperature (Figures 6, 7 and Supplementary Figures $\mathrm{S} 4, \mathrm{~S} 5) . K_{\mathrm{m}}$-value for oxaloacetate was always lower than that for malate in range of $20-50^{\circ} \mathrm{C}$, thus, it is considered that $S y \mathrm{MDH}$ always show higher affinity for oxaloacetate than malate within $20-50^{\circ} \mathrm{C}$ and the reaction direction of $S y \mathrm{MDH}$ tends to flow from oxaloacetate to malate within the growth temperature of Synechocystis 6803.

Our study revealed that $S y \mathrm{MDH}$ shows a higher affinity for substances produced through the reductive reaction than those produced through the oxidative reaction, similar to MDHs derived from anaerobic microorganisms in which the oxidative

\section{REFERENCES}

Bennett, B. D., Kimball, E. H., Gao, M., Osterhout, R., Van Dien, S. J., and Rabinowitz, J. D. (2009). Absolute metabolite concentrations and implied enzyme active site occupancy in Escherichia coli. Nat. Chem. Biol. 8, 593-599. doi: $10.1038 /$ nchembio. 186

Beyer, S., Gilch, S., Meyer, O., and Schmidt, I. (2009). Transcription of genes coding for metabolic key functions in Nitrosomonas europaea during aerobic and anaerobic growth. J. Mol. Microbiol. Biotechnol. 16, 187-197. doi: 10.1159/ 000142531

Broddrick, J. T., Rubin, B. E., Welkie, D. G., Du, N., Mih, N., Diamond, S., et al. (2016). Unique attributes of cyanobacterial metabolism revealed by improved genome-scale metabolic modeling and essential gene analysis. Proc. Natl. Acad. Sci. U.S.A. 113, E8344-E8353. doi: 10.1073/pnas.16134 46113

Cendrin, F., Chroboczek, J., Zaccai, G., Eisenberg, H., and Mevarech, M. (1997). Cloning, sequencing, and expression in Escherichia coli of the gene coding for malate dehydrogenase of the extremely halophilic archaebacterium Haloarcula marismortui. Biochemistry 32, 4308-4313. doi: 10.1021/bi00067 a020

Coleman, J. R., and Coleman, B. (1981). Inorganic carbon accumulation and photosynthesis in a blue-green alga as a function of external $\mathrm{pH}$. Plant Physiol. 67, 917-921. doi: 10.1104/pp.67.5.917
TCA cycle seems to be barely functioning. Cyanobacteria have been found to close the TCA cycle using various bypasses (Zhang and Bryant, 2011; Steinhauser et al., 2012; Xiong et al., 2014). However, the results in this study indicate that the oxidative TCA cycle of Synechocystis 6803 may be functionally linear, and not cyclic in nature, because $5 y \mathrm{MDH}$ preferentially undergoes a reductive reaction rather than an oxidative reaction and turns off the cyclic process of the oxidative TCA cycle.

\section{AUTHOR CONTRIBUTIONS}

MT designed the research, performed the experiments, analysed the data, and wrote the manuscript. SI analysed the data. HS performed the experiments. TO analysed the data and wrote the manuscript.

\section{FUNDING}

This work was supported by the Ministry of Education, Culture, Sports, Science and Technology, Japan, by a grant to TO, from ALCA (Project Name "Production of cyanobacterial succinate by the genetic engineering of transcriptional regulators and circadian clocks") (Grant No. JPMJAL1306), from the Japan Science and Technology Agency, and by JSPS KAKENHI Grantin-Aid for Scientific Research on Innovative Areas (Grant No. 16H06559).

\section{SUPPLEMENTARY MATERIAL}

The Supplementary Material for this article can be found online at: https://www.frontiersin.org/articles/10.3389/fpls.2018.00947/ full\#supplementary-material

Deutch, C. E. (2013). L-Malate dehydrogenase activity in the reductive arm of the incomplete citric acid cycle of Nitrosomonas europaea. Antonie Van Leeuwenhoek 104, 645-655. doi: 10.1007/s10482-013-9973-6

Eszes, C. M., Sessions, R. B., Clarke, A. R., Moreton, K. M., and Holbrook, J. J. (1996). Removal of substrate inhibition in a lactate dehydrogenase from human muscle by a single residue change. FEBS Lett. 399, 193-197. doi: 10.1016/S00145793(96)01317-8

Ge, Y. D., Cao, Z. Y., Wang, Z. D., Chen, L. L., Zhu, Y. M., and Zhu, G. P. (2010). Identification and biochemical characterization of a thermostable malate dehydrogenase from the mesophile Streptomyces coelicolor A3(2). Biosci. Biotechnol. Biochem. 74, 2194-2201. doi: 10.1271/bbb.100357

Harmsen, H. J., Kengen, H. M., Akkermans, A. D., Stams, A. J., and Vos, W. M. (1996). Detection and localization of syntrophic propionateoxidizing bacteria in granular sludge by in situ hybridization using $16 \mathrm{~S}$ rRNA-based oligonucleotide probes. Appl. Environ. Microbiol. 62, 1656-1663.

Hasunuma, T., Matsuda, M., and Kondo, A. (2016). Improved sugar-free succinate production by Synechocystis sp. PCC 6803 following identification of the limiting steps in glycogen catabolism. Metab. Eng. Commun. 3, 130-141. doi: 10.1016/j.meteno.2016.04.003

Honka, E., Fabry, S., Niermann, T., Palm, P., and Hensel, R. (1990). Properties and primary structure of the L-malate dehydrogenase from the extremely thermophilic archaebacterium Methanothermus 
fervidus. Eur. J. Biochem. 188, 623-632. doi: 10.1111/j.1432-1033.1990. tb15443.x

Huynen, M. A., Dandekar, T., and Bork, P. (1999). Variation and evolution of the citric-acid cycle: a genomic perspective. Trends Microbiol. 7, 281-291. doi: 10.1016/S0966-842X(99)01539-5

Ito, S., Takeya, M., and Osanai, T. (2017). Substrate specificity and allosteric regulation of a d-lactate dehydrogenase from a unicellular cyanobacterium are altered by an amino acid substitution. Sci. Rep. 7:15052. doi: 10.1038/s41598017-15341-5

Knoop, H., Gründel, M., Zilliges, Y., Lehmann, R., Hoffmann, S., Lockau, W., et al. (2013). Flux balance analysis of cyanobacterial metabolism: the metabolic network of Synechocystis sp. PCC 6803. PLoS Comput. Biol. 9:e1003081. doi: 10.1371/journal.pcbi.1003081

Labrou, N. E., and Clonis, Y. D. (1997). L-Malate dehydrogenase from Pseudomonas stutzeri: purification and characterization. Arch. Biochem. Biophys. 337, 103-114. doi: 10.3923/ajbkr.2011.478.485

Mangan, N. M., Flamholz, A., Hood, R. D., Milo, R., and Savage, D. F. (2016). $\mathrm{pH}$ determines the energetic efficiency of the cyanobacterial $\mathrm{CO}_{2}$ concentrating mechanism. Proc. Natl. Acad. Sci. U.S.A. 113, E5354-E5362. doi: 10.1073/pnas. 1525145113

Matsunaga, T., Takeyama, H., Sudo, H., Oyama, N., Ariura, S., Takano, H., et al. (1991). Glutamate production from $\mathrm{CO}_{2}$ by marine cyanobacterium Synechococcus sp. using a novel biosolar reactor employing light-diffusing optical fibers. Appl. Biochem. Biotechnol. 28:157. doi: 10.1007/BF0292 2597

Mikulášová, D., Kollárová, M., Miginiac-Maslow, M., Decottignies, P., Jacquot, J. P., Kutejová, E., et al. (1998). Purification and characterization of the malate dehydrogenase from Streptomyces aureofaciens. FEMS Microbiol. Lett. 159, 299-305. doi: 10.1016/S0378-1097(97)00567-3

Minárik, P., Tomásková, N., Kollárová, M., and Antalík, M. (2002). Malate dehydrogenases structure and function. Gen. Physiol. Biophys. 21, 257-265.

Molenaar, D., van der Rest, M. E., and Petrović, S. (1998). Biochemical and genetic characterization of the membrane associated malate dehydrogenase (acceptor) from Corynebacterium glutamicum. Eur. J. Biochem. 25, 395-403. doi: 10.1046/ j.1432-1327.1998.2540395.x

Muro-Pastor, M. I., and Florencio, F. J. (1992). Purification and properties of NADP-isocitrate dehydrogenase from the unicellular cyanobacterium Synechocystis sp. PCC 6803. Eur. J. Biochem. 203, 99-105. doi: 10.1111/j.14321033.1992.tb19833.x

Muro-Pastor, M. I., and Florencio, F. J. (1994). NADP(+)-isocitrate dehydrogenase from the cyanobacterium Anabaena sp. strain PCC 7120: purification and characterization of the enzyme and cloning, sequencing, and disruption of the icd gene. J. Bacteriol. 176, 2718-2726. doi: 10.1128/jb.176.9.2718-2726. 1994

Nakajima, T., Kajihata, S., Yoshikawa, K., Matsuda, F., Furusawa, C., Hirasawa, T., et al. (2014). Integrated metabolic flux and omics analysis of Synechocystis sp. PCC 6803 under mixotrophic and photoheterotrophic conditions. Plant Cell Physiol. 55, 1605-1612. doi: 10.1093/pcp/pcu091

Nakajima, T., Yoshikawa, K., Toya, Y., Matsuda, F., and Shimizu, H. (2017). Metabolic flux analysis of the Synechocystis sp. PCC $6803 \triangle n r t A B C D$ mutant reveals a mechanism for metabolic adaptation to nitrogenlimited conditions. Plant Cell Physiol. 58, 537-545. doi: 10.1093/pcp/ pcw233

Osanai, T., Imashimizu, M., Seki, A., Sato, S., Tabata, S., Imamura, S., et al. (2009). $\mathrm{ChlH}$, the $\mathrm{H}$ subunit of the $\mathrm{Mg}$-chelatase, is an anti-sigma factor for SigE in Synechocystis sp. PCC 6803. Proc. Natl. Acad. Sci. U.S.A. 106, 6860-6865. doi: 10.1073/pnas.0810040106

Osanai, T., Oikawa, A., Shirai, T., Kuwahara, A., Iijima, H., Tanaka, K., et al. (2014). Capillary electrophoresis-mass spectrometry reveals the distribution of carbon metabolites during nitrogen starvation in Synechocystis sp. PCC 6803. Environ. Microbiol. 16, 512-524. doi: 10.1111/1462-2920.12170

Osanai, T., Shirai, T., Iijima, H., Nakaya, Y., Okamoto, M., Kondo, A., et al. (2015). Genetic manipulation of a metabolic enzyme and a transcriptional regulator increasing succinate excretion from unicellular cyanobacterium. Front. Microbiol. 6:1064. doi: 10.3389/fmicb.2015.01064

Owen, O. E., Kalhan, S. C., and Hanson, R. W. (2002). The key role of anaplerosis and cataplerosis for citric acid cycle function. J. Biol. Chem. 277, 30409-30412. doi: 10.1074/jbc.R200006200
Pitson, S. M., Mendz, G. L., Srinivasan, S., and Hazell, S. L. (1999). The tricarboxylic acid cycle of Helicobacter pylori. Eur. J. Biochem. 260, 258-267. doi: 10.1046/j. 1432-1327.1999.00153.x

Rubin, B. E., Wetmore, K. M., Price, M. N., Diamond, S., Shultzaberger, R. K., Lowe, L. C., et al. (2015). The essential gene set of a photosynthetic organism. Proc. Natl. Acad. Sci. U.S.A. 112, 6634-6643. doi: 10.1073/pnas.1519220112

Singh, R., Lemire, J., Mailloux, R. J., and Appanna, V. D. (2008). A novel strategy involved in [corrected] anti-oxidative defense: the conversion of $\mathrm{NADH}$ into NADPH by a metabolic network. PLoS One 3:e2682. doi: 10.1371/journal.pone. 0002682

Steinhauser, D., Fernie, A. R., and Araújo, W. L. (2012). Unusual cyanobacterial TCA cycles: not broken just different. Trends Plant Sci. 17, 503-509. doi: 10.1016/j.tplants.2012.05.005

Stetter, K. O., Thomm, M., Winter, J. G. W., Juber, H., Zillig, W., Janecovic, D., et al. (1981). Methanothermus fervidus sp., a novel extremely thermophilic methanogen isolated from an icelandic hot spring. Zentralbl. Bakterial. Hyg. I Abt. Orig. C 2, 166-178. doi: 10.1016/S0721-9571(81)80038-5

Takahashi-Îñiguez, T., Aburto-Rodríguez, N., Vilchis-González, A. L., and Flores, M. E. (2016). Function, kinetic properties, crystallization, and regulation of microbial malate dehydrogenase. J. Zhejiang Univ. Sci. B 17, 247-261. doi: 10.1631/jzus.B1500219

Takeya, M., Hirai, M. Y., and Osanai, T. (2017). Allosteric inhibition of phosphoenolpyruvate carboxylases is determined by a single amino acid residue in cyanobacteria. Sci. Rep. 24:41080. doi: 10.1038/srep41080

Thompson, H., Tersteegen, A., Thauer, R. K., and Hedderich, R. (1997). Two malate dehydrogenases in Methanobacterium thermoautotrophicum. Arch. Microbiol. 170, 38-42. doi: 10.1007/s002030050612

van Kuijk, B. L., and Stams, A. J. (1996). Purification and characterization of malate dehydrogenase from the syntrophic propionate-oxidizing bacterium strain MPOB. FEMS Microbiol. Lett. 144, 141-144. doi: 10.1111/j.1574-6968. 1996.tb08520.x

Wan, N., DeLorenzo, D. M., He, L., You, L., Immethun, C. M., Wang, G., et al. (2017). Cyanobacterial carbon metabolism: fluxome plasticity and oxygen dependence. Biotechnol. Bioeng. 114, 1593-1602. doi: 10.1002/bit.26287

Wise, D. J., Anderson, C. D., and Anderson, B. M. (1997). Purification and kinetic characterization of Haemophilus parasuis malate dehydrogenase. Arch. Biochem. Biophys. 344, 176-183. doi: 10.1006/abbi.1997.0186

Wu, H., Li, Z. M., Zhou, L., and Ye, Q. (2007). Improved succinic acid production in the anaerobic culture of an Escherichia coli pflB ldhA double mutant as a result of enhanced anaplerotic activities in the preceding aerobic culture. Appl. Environ. Microbiol. 73, 7837-7843. doi: 10.1128/AEM.01546-07

Wynne, S. A., Nicholls, D. J., Scawen, M. D., and Sundaram, T. K. (1996). Tetrameric malate dehydrogenase from a thermophilic Bacillus: cloning, sequence and overexpression of the gene encoding the enzyme and isolation and characterization of the recombinant enzyme. Biochem. J. 317( $\mathrm{Pt} \mathrm{1),}$ 235-245. doi: 10.1042/bj3170235

Xiong, W., Brune, D., and Vermaas, W. F. (2014). The $\gamma$-aminobutyric acid shunt contributes to closing the tricarboxylic acid cycle in Synechocystis sp. PCC 6803. Mol. Microbiol. 93, 786-796. doi: 10.1111/mmi.12699

Xiong, W., Morgan, J. A., Ungerer, J., Wang, B., Maness, P. C., and Yu, J. (2015). The plasticity of cyanobacterial metabolism supports direct $\mathrm{CO}_{2}$ conversion to ethylene. Nat. Plants 1:15053. doi: 10.1038/nplants.2015.53

Zhang, S., and Bryant, D. A. (2011). The tricarboxylic acid cycle in cyanobacteria. Science 334, 1551-1553. doi: 10.1126/science. 1210858

Zhang, S., and Bryant, D. A. (2015). Biochemical validation of the glyoxylate cycle in the cyanobacterium Chlorogloeopsis fritschii strain PCC 9212. J. Biol. Chem. 290, 14019-14030. doi: 10.1074/jbc.M115.648170

Conflict of Interest Statement: The authors declare that the research was conducted in the absence of any commercial or financial relationships that could be construed as a potential conflict of interest.

Copyright (c) 2018 Takeya, Ito, Sukigara and Osanai. This is an open-access article distributed under the terms of the Creative Commons Attribution License (CC BY). The use, distribution or reproduction in other forums is permitted, provided the original author(s) and the copyright owner(s) are credited and that the original publication in this journal is cited, in accordance with accepted academic practice. No use, distribution or reproduction is permitted which does not comply with these terms. 